\title{
Infective endarteritis affecting the left pulmonary artery after anatomical correction of complete transposition of the great arteries
}

\author{
J M PARSONS, R P MARTIN, R RADLEY SMITH \\ From the Paediatric Surgical Unit, Harefield Hospital, Harefield, Middlesex
}

SUMMARY Clinical features of infective endocarditis developed in a two year old boy. He had successfully undergone anatomical correction of complete transposition of the great arteries during the neonatal period. At routine investigation one year later he showed evidence of importane supravalvar pulmonary stenosis. He remained symptom free until endocarditis developed Streptococcus pneumoniae was isolated from serial blood cultures. Despite prompt treatment with specific intravenous antibiotic treatment the patient died of overwhelming sepsis. At necropsy the stenosed portion of the left pulmonary artery was seen to be the site of infection.

Although anatomical correction for complete transposition of the great arteries was first described over ten years ago the operation is still a comparatively new procedure. ${ }^{1-3}$ There is much interest in the long term follow up of patients undergoing this operation. Supravalvar pulmonary stenosis appears to be an important finding. ${ }^{4}$ Infective endocarditis, however, is a complication that has not previously been reported.

We describe a fatal case of fulminating infection that occurred at the site of supravalvar pulmonary stenosis after this operation.

\section{Case report}

A two year boy was admitted to hospital after a short history of fever and non-specific malaise. As a neonate he had undergone anatomical correction of complete simple transposition of the great arteries. The pulmonary artery was reconstructed by the method described by Lecompte et al. ${ }^{6}$ Dura was used to repair the defects left in the pulmonary trunk after the transfer of the coronary arteries.

There were no operative or early postoperative complications and he was routinely investigated when he was 14 months old. Cardiac catheterisation showed the presence of considerable supravalvar Requests for reprints to Dr J M Parsons, Department of Paediatric Cardiology, Guy's Hospital, St Thomas Street, London SE1 9RT. pulmonary stenosis with pressure drop on with-o drawal of $75 \mathrm{~mm} \mathrm{Hg}$ and simultaneous right and lefo ventricular systolic pressures of $95 \mathrm{~mm} \mathrm{Hg}$ and $80^{\circ}$ $\mathrm{mm} \mathrm{Hg}$ respectively. A right ventricular angiogramêp (fig 1) showed severe narrowing of the distal pulmonary trunk extending into the left proximal pulmonary artery. Because he was symptom free with good righe ventricular function non-urgent surgical repair of the pulmonary stenosis was planned. He remained symptom free until three weeks before admission. His initial symptoms were attributed to a possible infection of the upper respiratory tract for which hiso general practitioner prescribed a week's course of antibiotics. Because there was no clinicag improvement he was admitted to hospital.

He had a fever $\left(38^{\circ} \mathrm{C}\right)$. He appeared clinically? anaemic and was peripherally cyanosed with cooh extremities. He had a sinus tachycardia and clinicaf evidence of right ventricular hypertrophy. There was 0 a systolic thrill and grade $4 / 6$ ejection murmur that was loudest over the left second intercostal space There were no other abnormal findings.

The initial chest $x$ ray was normal. Cross sectiona echocardiography confirmed the presence of righ ${ }^{\infty}$ ventricular hypertrophy with severe supravalvar pul- 0 monary stenosis. It did not show any evidence oP infective vegetations. His haemoglobin was $7.7 \mathrm{mg} / \mathfrak{R}$ with a hypochromic microcytic blood film. He had ${ }_{2}$ leucocytosis of $18.5 \times 10^{6} / 1$ (predominantly neutro- 


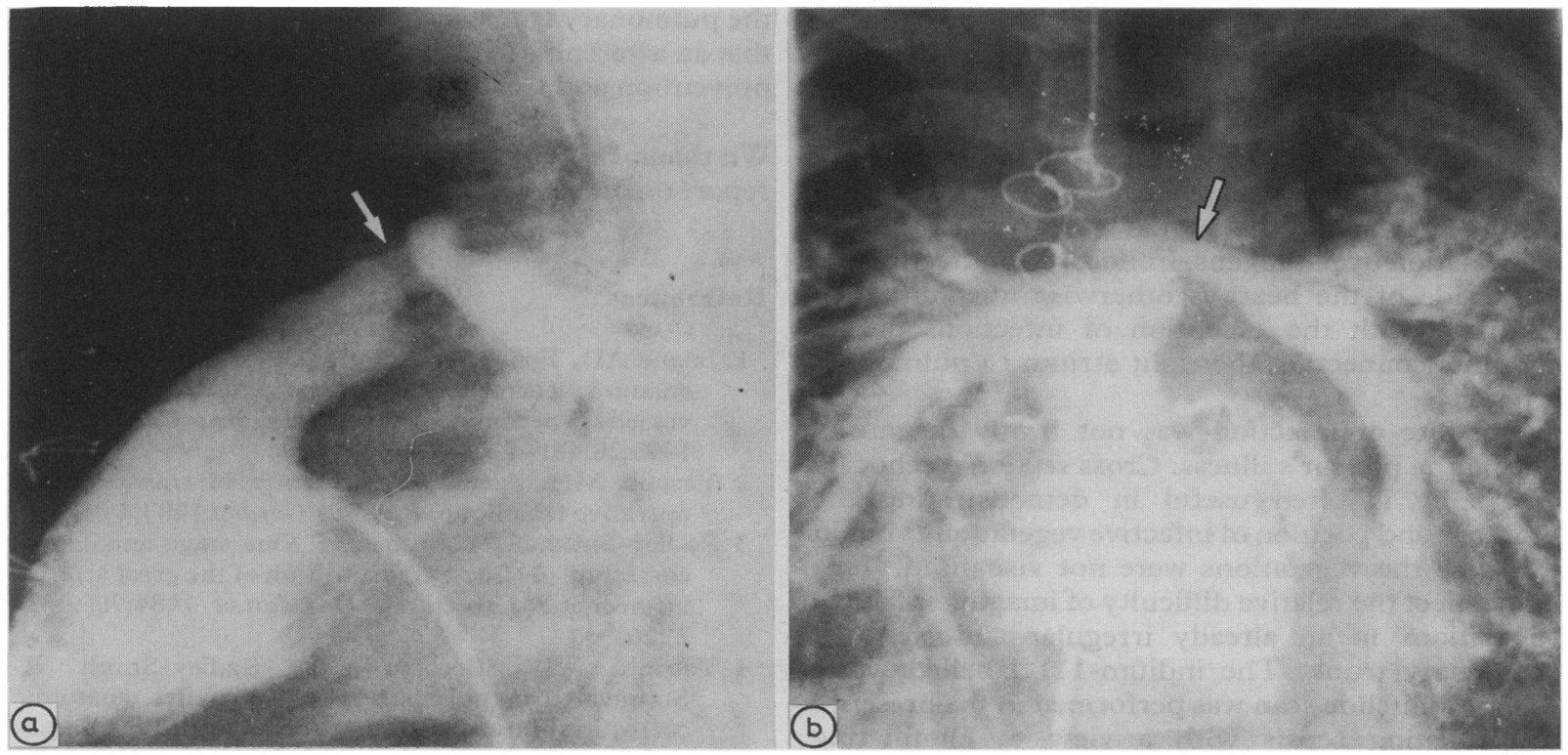

Fig 1 Right ventricular angiograms in anteroposterior (a) and lateral projections (b) showing supravalvar stenosis in the main pulmonary trunk and in the left branch pulmonary artery (arrows).

phils). Infective endocarditis was considered the likely diagnosis and serial blood cultures were taken. After 48 hours these grew Streptococcus pneumoniae and treatment with intravenous benzyl penicillin ( 50 $\mathrm{mg} / \mathrm{kg}$, four hourly) was started immediately. A few hours later presumed septicaemic shock developed and he suffered an asystolic cardiac arrest, from which he was resuscitated. He became oliguric and uraemic with signs of disseminated intravascular coagulopathy. He developed acute renal failure,

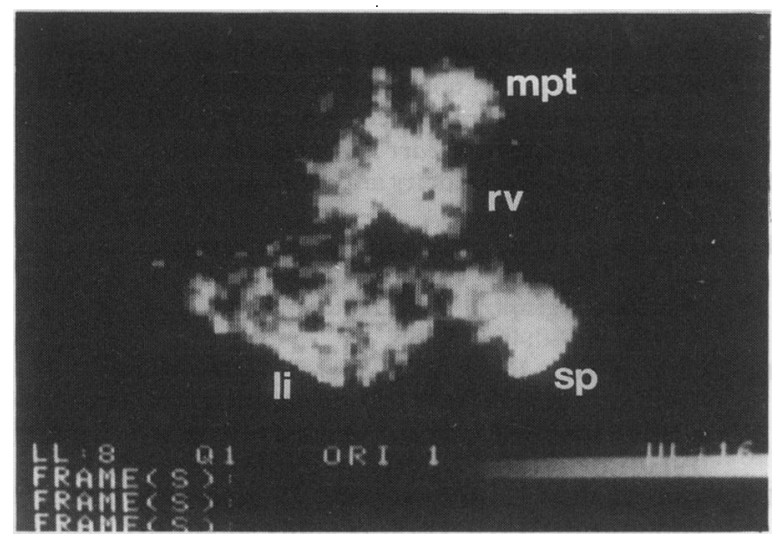

Fig 2 An indium-111 labelled white cell radionuclide scan showing an area of increased uptake representing the heart (right ventricle, $r v$ ) which extends into the region of the main pulmonary trunk (mpt). The liver (li) and spleen (sp) can be seen below the diaphragm. requiring peritoneal dialysis. Three days later he remained febrile with a persistent leucocytosis. Repeated blood cultures were all negative.

In view of persisting sepsis and his deteriorating condition he was treated with a broad spectrum antibiotic (cefuroxime $100 \mathrm{mg} / \mathrm{kg} / 24 \mathrm{~h}$ ) on the second day. Aminoglycosides were avoided because of his renal failure. An indium-111 (fig 2) labelled white cell radionuclide scan showed a possible area of increased uptake in the region of the pulmonary trunk. The child's condition deteriorated rapidly and he died before any surgical intervention could be performed. Necropsy showed a hypertrophied right ventricle with a healthy pulmonary valve. The main pulmonary trunk was stenosed and the narrowing extended into the left pulmonary artery. Infective vegetations occluded the left pulmonary artery.

\section{Discussion}

The risk of infective endocarditis is considerably increased in children with congenital heart disease, and the disease can occur with almost any lesion.? Surgical repair, both palliative and corrective, can affect the subsequent risk of developing infective endocarditis. ${ }^{89}$ We identified supravalvar pulmonary stenosis as an important complication after anatomical correction for complete transposition of the great arteries; it was more common when the operation was performed in the neonatal period. ${ }^{45}$ Turbulent blood flow distal to the stenotic lesion may 
increase the risk of developing infective endarteritis.

Rodbard first described how endocarditis tends to occur at sites where blood flow velocity is high..$^{10}$ This may be because excessive flow causes a venturi effect, creating a distal area of low pressure and perfusion. The intima is also damaged in these areas, and both factors may make the region more susceptible to colonisation by pathogens. Endocarditis affecting the right side of the heart is otherwise uncommon in children, with the exception of infections of the conduits connecting the right atrium to pulmonary artery.

The site of infection was not firmly diagnosed during the patient's illness. Cross sectional echocardiography is often useful in demonstrating the presence and position of infective vegetations ${ }^{11}$ but in this case the vegetations were not visualised. This may reflect the relative difficulty of imaging infective vegetations in an already irregular and stenosed pulmonary trunk. The indium-111 labelled white cell radionuclide scan was performed in the presence of persisting sepsis with a view to eliminating additional sites of infection. ${ }^{12}$ The result was of value in localising the infection to the heart and excluding the presence of intracerebral and intraabdominal infection. There was increased uptake in the region of the ventricular mass extending to the pulmonary trunk. Indium-111 labelled white cell radionuclide imaging, therefore, could potentially be of value in localising infections of the distal pulmonary trunk.

The commonest organisms isolated from patients with infective endocarditis are the Streptococcus viridans group, which account for $50^{\circ}{ }_{0}$ of all culture positive cases. ${ }^{13}$ Endocarditis caused by Streptococcus pneumoniae is uncommon. In normal hearts it can occur as a complication of lobar pneumonia or meningitis and has been recognised in children with right atrial isomerism and asplenia syndrome. ${ }^{14} \mathrm{We}$ know of no specific reasons why this patient was infected with this organism because we could not identify the the portal of entry.

Once he was admitted to hospital the infective endocarditis was quickly diagnosed and appropriate treatment was started. Despite this the infection could not be adequately controlled. Operation was considered but the development of rapidly deteriorating cardiac and renal function precluded this. Earlier referral to hospital might have improved the outcome. It is possible that early correction of supravalvar pulmonary stenosis could prevent this serious complication. Technical modifications of the operation may also help by reducing the incidence of supravalvar pulmonary stenosis.

Infective endocarditis may develop after anatomical correction for complete transposition of the great arteries. The possibility of infection within the pulmonary trunk should be considered. We hop that an awareness of this complication will help in its్ prevention and treatment.

We thank Professor M H Yacoub for allowing us t report on one of his patients.

\section{References}

1 Jatene AD, Fontes VF, Paulista PP, et al. Successfü anatomic correction of transposition of the great vessels. A preliminary report. Arq Bras Cardiol Bra $\overrightarrow{\mathrm{E}}$ 1975;28:461-4.

2. Yacoub MH. Anatomic correction of transposition operative technique. Paediatr Cardiol 1983;4:61-6. के

3 Radley-Smith R, Yacoub $\mathrm{MH}$. One stage anatomical correction of simple transposition of the great arteries in neonates [Abstract]. Circulation 1984;70(suppo 2):26.

4 Yacoub $\mathrm{MH}$, Bernhard A, Radley-Smith R? Supravalvular pulmonary stenosis after anatomi correction of transposition of the great arteries; cause and prevention. Circulation 1982;66(suppl 1):193-7. $\overrightarrow{0}$

5 Martin RP, Ladusans EJ, Parsons JM, Keck E, Radleye् Smith R, Yacoub MH. Incidence and site of pulmonary stenosis after anatomical correction of transposi tion of the great arteries [Abstract] $\mathrm{Br}$ Heart 1988;59:122-3.

6 Lecompte Y, Zannini L, Hazan E, et al. Anatomica correction of transposition of the great arteries, a new technique without use of prosthetic conduit. Thoracic Cardiovasc Surg 1981;82:629-31.

7 Johnson DH, Rosenthal A, Nadas AS. A 40 year review of bacterial endocarditis in infancy and childhood? Circulation 1975;51:581-8.

8 Shah P, Singh WSA, Rose V, Keith JD. Incidence of bacterial endocarditis in ventricular septal defects Circulation 1966;34:127-31.

9 Karl T, Wensley D, Stark J, de Leval M, Rees P, Taylo롱 JFN. Infective endocarditis in children with congen?. ital heart disease: comparison of selected features if patients with surgical correction or palliation an those without. Br Heart J 1987;58:57-65.

10 Rodbard S. Blood velocity and endocarditis. Circulation 1963;27:18-28.

11 Martin RP, Meltzer RS, Chia BL, Stinson EB, Rakow . ski H, Popp RL. Clinical utility of two dimensionafs echocardiography in infective endocarditis. $\mathrm{Am}$ Cardiol 1980;46:379-85.

12 Coleman RE, Black RE, Welch DM, Maxwell JG N Indium-111 labelled leukocytes in the evaluation of suspected abdominal abscesses. Am $J$ Surg 1980;139:99-104.

13 Moulsdale MT, Eykyn SJ, Phillips I. Infectivø endocarditis 1970-1979. A study of culture positive cases in St. Thomas's Hospital. $Q J$ Mes 1980;49:315-28.

14 Anderson RH, Macartney FJ, Shinebourne EA, Tyna尺ి M. Paediatric cardiology. Edinburgh: Churchif Livingstone, 1987:1230. 